\title{
'Alleen tot nut en vermaak der Sexe ingerigt': een verkenning van De Dames-post (1785)
}

LOTTE JENSEN

Een schets van het eerste oorspronkelijk Nederlandse tijdschrift voor een vrouwelijk lezerspubliek.

Op 12 januari 1785 verschijnt bij de Amsterdamse drukker Johannes Weppelman het eerste nummer van De Dames-post. ${ }^{\mathrm{I}}$ Het blad, dat in wekelijkse afleveringen uitkomt, kost anderhalve stuiver en kan bij verschillende boekverkopers in het land worden verkregen. Ieder nummer beslaat vier pagina's die zijn gevuld met nieuwsberichten en divers mengelwerk, waaronder gedichten, verhalen en lezersbrieven. De inhoud van $D e$ Dames-post is gevarieerd, en zowel informatief als vermakelijk van aard.

Op de achttiende-eeuwse tijdschriftenmarkt neemt De Dames-post een bijzondere positie in: het lijkt het eerste oorspronkelijk Nederlandse tijdschrift te zijn dat speciaal bedoeld is voor een vrouwelijk lezerspubliek. Suzan van Dijk en Dini Helmers vestigden in I99r al de aandacht op De Dames-post. ${ }^{2}$ In hun artikel over de stand van zaken betreffende de Nederlandse vrouwentijdschriften in de achttiende eeuw concluderen zij dat dit eigenlijk het enige oorspronkelijk Noord-Nederlandse vrouwentijdschrift voor deze periode is dat het tot publicatie heeft gebracht, en waarvan bovendien exemplaren geconsulteerd kunnen worden. Deze conclusie wordt overigens onder het nodige voorbehoud getrokken. Zij wijzen er namelijk op dat er nog maar weinig systematisch onderzoek is verricht naar achttiende-eeuwse Nederlandse vrouwentijdschriften. Een grondige bestudering van de pers voor vrouwen hier te lande zal dan ook moeten uitwijzen of er naast De Dames-post nog andere oorspronkelijk Nederlandse vrouwenbladen te koop waren. Zo zijn bijvoorbeeld twee titels recentelijk nog boven water gekomen, namelijk De recensent voor vrouwen (1795) en Weekblad voor vrouwen (1795). Maar van beide tijdschrifțen, die vermeld worden in de naamlijst van Saakes, zijn helaas geen exemplaren bekend. ${ }^{3}$

Voor de negentiende eeuw is de stand van het onderzoek iets gunstiger. In 1979 verscheen in De negentiende eeuw een 'bibliografie vrouwentijdschriften I80o-1920 in het bezit van de UBA en IAV'. In 1992 yolgde een boek met uitvoerige bibliografische beschrijvingen van vrouwentijdschriften uit de periode $1800-1945$ van de hand van Claar Willems-Bierlaagh. ${ }^{4}$ De Nederlandse vrouwentijdschriften van ná I8oo zijn dus voor een deel geïnventariseerd, maar ook hier ontbreekt de inhoudelijke studie van deze periodieken grotendeels. Alleen het door Anna-Barbara van Meerten Schilperoort geredigeerde Penélopé (r821-1835) trekt weleens de aandacht van onderzoekerss, evenals de vroegfeministische tijdschriften Ons Streven (I870-1878) en Onze Roeping (1870-1873). ${ }^{6}$

De Engelse, Franse en Duitse vrouwenpersgeschiedenis zijn, in tegenstelling tot de Nederlandse, al uitgebreid voorwerp van onderzoek geweest. Om in kort bestek 
enkele belangrijke studies en tijdschriften te noemen: de vroegste Engelse vrouwenbladen zijn uitvoerig geclassificeerd en beschreven door onder anderen Monica Stearns (I930), Cynthia White (I970) en Kathryn Shevelow (I989). ${ }^{7}$ Als vroegste vrouwentijdschriften worden The Ladies' Mercury (1693) en The Female Tatler (1709I7IO) genoemd. De Franse vrouwenpers wordt onder meer besproken in de studies van Patouillet (1928) en Sullerot $(1966) .{ }^{8}$ Van recentere datum is Traces de femmes. Présence féminine dans le journalisme francais du XVIIIe siècle van Suzan van Dijk (Maarssen/ Amsterdam, I988). Vanaf ongeveer 1740 verschijnen verschillende Franstalige vrouwenbladen onder titels als Amusements du beau sexe (1740-174I) en Amusements de la Toilette ( $\mathrm{r} 755-1756)$. De Duitse vroege vrouwenpers ten slotte is door onder anderen Edith Krull (1930) en Sabine Schumann ( 1980 ) onderzocht. ${ }^{9}$ Het spectatoriale Die vernünftigen Tadlerinnen van het echtpaar Gottsched (I724-I725) richt zich als eerste tot een vrouwelijk publiek; later verschijnen ook door vrouwen geredigeerde vrouwentijdschriften, zoals Für Hamburgs Töchter (1779) van Ernestine Hofmann en Pomona (1783-I784) van Sophie la Roche.

Uit deze opsomming blijkt dat er in het buitenland reeds veel aandacht is besteed aan achttiende-eeuwse vrouwentijdschriften. De stand van het onderzoek in Nederland steekt hier schril bij af. Er bestaat, met andere woorden, een duidelijke lacune in de Nederlandse vrouwen(literatuur)- en persgeschiedenis. Met het opvullen van deze leemte is inmiddels wel een begin gemaakt: in 1997 is het Nwo-project 'Schrijfsters en hun publieken, I700-I880' van start gegaan. Binnen dit project is het promotieonderzoek 'Vrouwen en de pers in Nederland, 1700-1870', waaraan ondergetekende de komende jaren zal werken, programmatisch opgenomen. De resultaten zullen te zijner tijd volgen. Nu kan het zinvol zijn één tijdschrift eens wat nader te bekijken, en wel het reeds genoemde De Dames-post. Het moge overigens duidelijk zijn dat bij de huidige stand van het onderzoek lang niet alle vragen die dit tijdschrift oproépt, beantwoord kunnen worden en dat de volgende excurs het karakter van een verkenning draagt.

De Dames-post bestaat steeds uit twee hoofdrubrieken: 'nieuwsbrieven' en 'mengelstukken'. De eerste hoofdrubriek bevat een selectie nieuwsberichten, de tweede is gevuld met verhalen, gedichten, spreuken en lezersbrieven. De Dames-post heeft enerzijds iets weg van de populaire nieuwstijdingen of de Franse gazettes, omdat er korte verslagen van actuele gebeurtenissen in staan. Anderzijds is ook de spectatoriale invloed duidelijk aanwezig: de (al dan niet fictieve) lezersbrieven hebben een duidelijke plaats in het tijdschrift en de redacteur van De Dames-post poogt middels de beantwoording van deze brieven een vertrouwensrelatie met zijn lezeressen op te bouwen. Van een echte spectatorfiguur, die als censor morum optreedt, is echter geen sprake. Niet alleen treedt de redacteur maar zelden op de voorgrond, ook de inhoud van het mengelwerk is te divers van aard. Bovendien wordt, zoals gezegd, de helft van het tijdschrift ingenomen door de nieuwsberichten.

Het nieuws is afkomstig uit grote buitenlandse steden zoals Parijs, Londen, Napels, Berlijn en Kopenhagen. Slechts eenmaal is ook een bericht uit het binnenland opgenomen: het betreft een verslag van een brand in de Jacobiner of Grote Kerk te Leeuwarden. Er wordt een lange opsomming gegeven van goederen die tijdelijk in het raadhuis zijn ondergebracht en die de eigenaars daar kunnen komen ophalen (nr.6, I6 februari). Soms zijn de nieuwsberichten louter informatief van aard, zoals het zojuist genoemde bericht uit Leeuwarden, of de mededeling dat er in Napels en de nabije omgeving dertien kloosters zijn vernietigd (nr.2, Ig januari). Maar veelal hebben de nieuwsberichten een onderhoudend karakter, in die zin dat ze amusementswaarde bezitten. Zo wordt er in het openingsnummer gemeld dat een vrouw in Carthagena van een monstrueus kind is bevallen. Het tweede nummer bevat het sensationele nieuwtie dat er in Xalapa een man van honderdtweeëntwintig jaar oud woont. Deze grijsaard werd in 1664 geboren in het dorp Tepejo, trouwde op zijn vijfenzeventigste en leidt thans een gelukkig leven als vader van tien kinderen. In weer een latere aflevering kan men lezen hoe een man uit Versailles zijn echtgenote om het leven bracht: hij sloeg haar met een kandelaar de hersens in (nr.I4, I3 april).

Opvallend is de afwezigheid van politieke nieuwsberichten in De Dames-post, terwijl er op dat vlak over de situatie in Europa van dat moment toch genoeg te melden was. Dit hangt waarschijnlijk samen met het feit dat het tijdschrift speciaal voor een vrouwelijk lezerspubliek bedoeld was. Dat diende zich niet te verdiepen in staatszaken, maar kon zich vermaken met onderhoudende nieuwtjes. De redacteur van $\mathrm{De} \mathrm{Da}$ mes-post weerde aldus de politieke realiteit uit zijn blad. Dat het een mannelijke redacteur betrof, blijkt overigens uit de aanhef van lezersbrieven met 'myn heer'. Een soortgelijke observatie is door Suzan van Dijk gedaan voor onder andere de laatste twee jaargangen van het Franse Journal des Dames (1759-1778), geredigeerd door de heer Dorat. De inhoud van dit vrouwentijdschrift werd in die jaren duidelijk afgestemd op het geïntendeerde publiek: met geen woord werd gerept over de Amerikaanse onafhankelijkheidsoorlog, die toch de gemoederen van velen bezig hield. Versjes, theaternieuws en verhalen namen daarentegen een prominente plaats in. ${ }^{\mathrm{x}}$ Overigens wordt in één aflevering van De Dames-post wel een politiek onderwerp aangesneden, namelijk in een anonieme lezersbrief. Deze gaat over de angst van de $\mathrm{Ne}-$ derlanders, en met name het vrouwelijke deel van de bevolking, voor de uitheemse legertroepen die het land op dat moment naderen. De schrijver van de brief excuseert zich echter onmiddellijk voor het onvrouwelijke thema van zijn brief, wetende dat $D$ Dames-post 'met vermyding van alle Staatszaaken alléén tot nut en vermaak der Sexe [is] ingerigt' (nr.6, I6 februari).

Dat De Dames-post speciaal voor vrouwen bedoeld was, blijkt ook uit de inhoud van de rubriek 'mengeIstukken'. Zo wordt deze maar liefst vier afleveringen lang gevuld met een (fictieve) briefwisseling tussen 'eene Amsterdamsche Dame en haare vriendin op de Veluwe'. 'De verstandigsten onder de schoone sexe zullen deze met genoegen lezen', meent de redacteur van De Dames-post (nr.Ix, 23 maart). In de briefwisseling wordt de mondaine en weelderige levenswijze van de Amsterdamse vrouw Henrietta gecontrasteerd met het eenvoudige boerenbestaan van haar Veluwse vriendin Margareta. De Amsterdamse slaapt iedere dag lang uit, terwijl haar vriendin met het rijzen van de zon opstaat. De Amsterdamse laat 's middags haar kapsel drie uur lang met de krultang verzorgen, terwijl de Veluwse de keuken aan het bestieren is Ook de lectuur van de beide dames is verschillend: de Amsterdamse gaat, wanneer zij zich verveelt, haar nieuwe Franse boeken lezen, aangezien de Hollandse boeken volgens haar stadsvriendinnen 'zonder smaak' zijn. Boeken van Engelse schrijvers zoals Dodridge, Young, Hervey en Bennet legt zij ook liever terzijde, omdat ze die te melancholiek vindt. De Veluwse daarentegen leest haar vader graag voor uit de heldendichten David van de Hollandse Lucretia Wilhelmina van Merken ( 1767 ) en zij heeft juist hoge achting voor de genoemde Engelse auteurs.

Voorts beschrijft de pasgetrouwde Amsterdamse dame alle nieuwe gedragsregels die ze heeft moeten leren, toen ze van het platteland naar de hoofdstad verhuisde. Zo moest zij haar echtgenoot voortaan met 'Myn Heer' in plaats van 'lieve man' aanspreken, niet omzien wanneer hij met andere dames 'galantiseerde', het gebruikelijke ge- 
Dat de lezeressen van De Dames-post de levenswijze van de eenvoudige Veluwse vrouw dienden te prefereren boven die van de in luxe badende stedelijke dame, wordt gaandeweg de briefwisseling wel duidelijk. De Veluwse keurt het gedrag van haar Amsterdamse vriendin, die vroeger zo verstandig, bedachtzaam en godsvruchtig was, namelijk in alle toonaarden af. De briefwisseling tussen de beide vrouwen moest de lezeressen van De Dames-post dan ook niet alleen amuseren, maar ook stichten. De boodschap luidde uiteraard dat een verstandig en godvruchtig leven verkozen moest worden boven een zedeloos en goddeloos bestaan.

Ook het uitvoerige verslag van een florerend Indisch vrouwentoneelgezelschap lijkt met het oog op de vrouwelijke doelgroep in de rubriek 'mengelstukken' te zijn opgenomen (nr.9, 9 maart). De schrijver verhaalt hoe aan het hof van Tippoo-Saïb meisjes vanaf hun vierde en vijfde jaar tot danseres, musicienne en actrice worden opgeleid. De jonge meisjes brengen vooral intriges op de planken, bijvoorbeeld over vrouwen die samenspannen om een jaloerse man om de tuin te leiden. Hun uiterlijk wordt uitvoerig beschreven: ze dragen de prachtigste kleding en sieraden. Overigens vormt de belangstelling voor het vreemde en het exotische een constante factor in $\mathrm{De}$ Dames-post. In de nieuwsberichten wordt diverse malen aandacht besteed aan vorstelijke Afrikaanse en Ottomaanse personen, terwijl de mengelrubriek een aantal weken gevuld wordt met 'eene Indiaansche liefdesgeschiedenis'. Deze goût exotique kenmerkt niet alleen De Dames-post, maar was, zoals bekend, een wijd verbreid verschijnsel in de tweede helft van de achttiende eeuw. ${ }^{\text {1i }}$

Een ander op vrouwen toegesneden onderwerp uit de 'mengelstukken' vormt het huwelijk. Eenmaal wordt een lofdicht op het huwelijk van een niet bij naam genoemde 'dichteresse' geplaatst. Ook worden twee uit Engeland afkomstige brieven afgedrukt, waarin de mannelijke schrijvers klagen over het feit dat Engelse dames zo moeizaam hun jawoord geven. Tegen de tijd dat Britse vrouwen instemmen met een huwelijk is ofwel de dood nabij ofwel alle uiterlijke schoonheid vervlogen. In een volgende aflevering antwoordt de schrijver van De Dames-post dat de Hollandse vrouwen gelukkig niet zo besluiteloos zijn, en 'wel weeten waar zy moeten gaan staan' in huwelijkse kwesties (nr.4, 2 februari). Om de afkeurenswaardige houding van de Engelse vrouwen nog eens te onderstrepen wordt vervolgens een brief van een Franse juffrouw geplaatst, die maar al te graag naar het huwelijksaltaar 'vliegt'. De lezeressen van De Dames-post worden geacht uit dit alles hun conclusies te trekken: aangezien het leven slechts kort duurt en schoonheid vergankelijk is, dienen ze snel te trouwen. Opnieuw vormen de brieven niet alleen amusant maar ook stichtelijk leesvoer.

Inhoudelijk gezien is De Dames-post een internationaal georiënteerd tijdschrift. Zo worden in de zojuist genoemde brieven de nationale gewoonten van Engelse, Hollandse en Franse vrouwen met elkaar vergeleken en tegen elkaar afgewogen. Ook bevat het tijdschrift veel vertaald werk. De laatste vier afleveringen worden bijvoorbeeld grotendeels in beslag genomen door een uit het Engels vertaald verhaal over de gravin van Salisbury en koning Eduard III. Het eerder genoemde 'Indiaansche' liefdesverhaal is van Franse origine. Verder moet men niet vergeten dat op één bericht na, al het nieuws uit het buitenland afkomstig is.

Dit alles roept vragen op omtrent het oorspronkelijk Nederlandse karakter van De Dames-post. Hoe Nederlands is een tijdschrift dat een groot deel van zijn materiaal over de grenzen heen zoekt? De mogelijkheid dat de redacteur van De Dames-post een buitenlands (vrouwen)tijdschrift navolgde qua inhoud en opzet, kan niet worden uitgesloten. De Dames-post is, met andere woorden, misschien minder oorspronkelijk dan op het eerste gezicht verondersteld zou worden. Tegelijkertijd waarborgen de plaatsen waarop de vaderlandse vrouwen expliciet worden genoemd of aangesproken echter het oorspronkelijke karakter van De Dames-post. De briefwisseling tussen de Amsterdamse dame en Veluwse juffer is hiervan een duidelijk voorbeeld, evenals de anonieme brief waarin de angst van Hollandse vrouwen voor uitheemse militaire troepen centraal staat.

In juli 1785 , een halfjaar na het verschijnen van het eerste nummer, houdt $\mathrm{De} \mathrm{Da}$ mes-post plotseling op te bestaan. Er wordt in het laatste nummer geen melding gemaakt van de reden van de opheffing, dus wij kunnen voorlopig nog slechts gissen naar de oorzaken. Gaf de redacteur van De Dames-post soms de voorkeur aan andere of nieuwe bezigheden? Of liep het blad niet goed en besloot de uitgever zich van een verliesgevende post te ontdoen? Het feit dat het aantal verkooppunten dat onderaan iedere aflevering vermeld wordt per nummer gestaag daalt, lijkt in die richting te wijzen. Het zou kunnen dat de omstandigheden in Nederland op dat moment niet gunstig waren voor het uitbrengen van een vrouwentijdschrift. Een poging van Betje Wolff en Aagje Deken, in $\mathrm{I} 786$, om een vrouwentijdschrift op te zetten, strandde namelijk eveneens. Het ging om een navolging van het Duitse Pomona fur Teutschlands Töchtern ( 1783 ) van Sophie von la Roche. Het zou deels een vertaling worden van het Duitse tijdschrift en deels gevuld worden met stukken van eigen vinding. Tot een publicatie kwam het echter nooit; een inleiding en een begin van het eerste nummer zijn in handschrift overgeleverd. ${ }^{22}$ Margaretha Cambon-van der Werken daarentegen slaagde er wel in een bewerking van een Duits vrouwentijdschrift te publiceren. Van haar Algemeene Oeffenschool der Vrouwen, door een Genootschap van voornaame Vrouwen in Duitschland: uit het Hoogduitsch overgebragt, en ten gebruik der Nederlandsche Jufferschap geschikt ( $I 784-\mathrm{I} 785)$ zagen ten minste drie delen het licht. In de Vaderlandsche Letter-oefeningen verscheen een bespreking van de eerste twee delen, waaruit blijkt dat het hier niet louter om een vertaling ging, maar dat de schrijfster tevens enige aanpassingen had aangebracht voor het Nederlandse publiek. ${ }^{13}$ De Dames-post, de Algemeene Oeffenschool der Vrouwen en de onderneming van Wolff en Deken wijzen er in ieder geval op dat er initiatieven ontplooid werden om vrouwentijdschriften in de eigen taal te publiceren. Het zou echter nog even duren voordat die markt werkelijk tot bloei zou komen. Er verschenen in de eerste decennia van de negentiende eeuw twee tijdschriften die beide een vrij lange bestaansduur kenden: Elegantia of Tijdschrift van Mode, Luxe en Smaak voor Dames (1807-18I4) en het al eerder genoemde Penélopé of maandwerk aan het vrouwelijk geslacht toegewijd (I82I-I835). In de jaren daarna nam het aantal bladen explosief toe. Er kwamen allerlei handwerk-, mode- en lectuurbladen voor vrouwen uit, waaronder bladen als Erina. Nederlandsch magazijn voor vrouwen (1843-1853), Maria en Martha. Lektuur voor christenvrouwen (I844-1856) en Aglaja (1848-1864). Het vrouwentijdschrift ontwikkelde zich vanaf deze periode tot een florerend genre, waarvan het succes tot op de dag van vandaag voortduurt.

- > LOTTE JENSEN is beurspromovenda aan de Universiteit van Amsterdam en doet onderzoek naar 'Vrouwen en de pers in Nederland, 1700-1870'. 
I. De Dames-post. Behelzende: eenige zeldzaame gebeurtenissen, zedelyke vertoogen en verhaalen, nuttige berichten, zedekundige brieven en aarimerkingen, fraaije dichtstukjes, enz. Byëen verzameld in zes-en twintig weekbladen, Amsterdam, J. Weppelman, 1785 . Voor dit artikel is gebruik gemaakt van een exemplaar in de Universiteitsbibliotheek van Leiden; volgens de Centrale catalogus van dag-, nienws- en weekbladen van algemene inhoud in Nederland verschenen ( 1989 ) bevindt zich ook een exemplaar in de Muziekbibliotheek van het Haags Gemeentemuseum.

2. Suzan van Dijk en Dini Helmers, 'Nederlandse vrouwentijdschriften in de achttiende eeuw', in: Balans \& perspectief van de Nederlandse cultuurgeschiedenis. De productie, distributie en consumptie van cultuur, red. J.J. Kloek en WW. Mijnhardt, Amsterdam, 1991, 80.

3. Zie Naamlijst van Nederduitsche boeken, Amsterdam 1794-1853, 13 din. Daaruit deel II, 206 en 208.

4. A. Boeve e.a., "Bibliografie vrouwentijdschriften 1800-1920 in het bezit van UBA en IAV', in: De negentiende eetw 3 (I979), 3, 166-184; Claar Willems-Bierlaagh, Nederlandse urouwentijdschriften 1800-1945. Bibliografische lijst, Amsterdam, I992.

5. Het meest recentelijk door Arie-Jan Gelderblom, 'Schrijvende leidsvrouw en kindervriendin: Anna Barbara van Meerten-Schilperoort (1778-1853)', in: Nederlandse Letterkunde 2 (1997), 1, 29-44. Zie met name 39-42.

6. Zie bijvoorbeeld Ulla Jansz, Denken over sekse in de eerste feministische golf, Amsterdam, 1990, met name 38 -4I.

7. Bertha Monica Stearns, 'The first English periodical for women', in: Modern philology 28 (1930), 1, 45-59 en 'Early English periodicals for ladies', in: PMLA, vol. 48, 1933, 38-60; Kathryn
Shevelow, Women and print culture. The construction offemininity in the early periodical, London/ New York, 1989 ; Cynthia L. White, Women's magazines 1693-1968, London, I970.

8. L. Patouillet, Lémancipation des femmes et la presse en France jusqu'en 1870, Parijs, 1928; E. Sullerot, Histoire de la Presse féminine en France des origines à 1848 , Parijs, 1966 .

9. Edith Krull, Das Wirken der Frau im frühen deutschen Zeitschriftwesen, Charlottenburg, 1966; Sabine Schumann, "Das "lesiende Frauenzimmer": Frauenzeitschriften im I8. Jahrhundert', in: Die Frau von der Reformation zur Romantik. Die Situation der Frau vor dem Hintergrund der Literatur- und Sozialgeschichte, Herausgegeben von Barbara Becker-Cantarino, Bonn, 1980, 138-169.

Io. Suzan van Dijk, ' 1778 . Les femmes dans l'actualité', in: P. Jansen e.a., L'Année 1778 à travers la Presse traitée par ordinateur, Parijs, 1982, 157 .

II. Zie hierover P.J. Buynsters, Spectatoriale geschriften, Utrecht, 199I, 95-98.

12. Het handschrift bevindt zich in de Universiteitsbibliotheek te Leiden, signatuur: Ltk 493 .

13. Zie hierover Suzan van Dijk, 'Vrouwen en hun Republiek der Letteren. Internationale contacten tussen schrijfsters vóór de feministische golven', in: Tijdschrift voor urouwenstudies 17 (I996), 248. De recensie staat in Algemeene Vaderlandsche Letteroefeningen, 1785, deel I, 89-9x. Arrenberg maakt melding van drie delen voor de prijs van $f_{2}, 00$. Zie R. Arrenberg, Naamregister van de bekendste Nederduitsche boeken, welke sedert het jaar 1600 tot het jaar $176 \pm$ zyn uitgekomen [...]. Voorheen uitgegeven door Johannes van Abkoude [...]. Nu overzien, verbeterd en tot het jaar 1787 vermeerderd door Reinier Arrenberg, Leiden, I965, 16. Facsimile van de uitgave Rotterdam 1788 . 